tomorrow? Our early successes in repairing the mitral valve suggest that your grandchildren will do it better than we have done it.

I have never considered you a Stephen Paget in your view of the future of cardiac surgery. More likely, you epitomize Isaac Newton's allusion to the fact we have stood on your shoulders to see so far ahead. Sir, give robotic and computer-assisted surgery a chance to develop and time will prove either the value or folly. The conscience of the surgical and patient community will direct the course.

\section{Editor's note: A response from Dr Francis Robicsek}

Time will tell.

Francis Robicsek, $M D$

Charlotte, NC

The Journal of Thoracic and Cardiovascular Surgery Conflict of Interest Policy

To assure fairness to authors submitting work for consideration in The Journal of Thoracic and Cardiovascular Surgery, a mechanism exists for managing conflicts of interest. The editor and each of the section editors complete a "Conflict of Interest" form that identifies any and all relationships with commercial and other academic entities. When the editor has a potential conflict because of a relationship with another entity or author, the editor appoints an alternate editor from among the section editors or editorial board members who assumes the entire responsibility for final decisions on the manuscript in question. The editor does not read the reviews that are submitted nor engage in discussing the manuscript prior to the final decision. When the conflict of interest involves a section editor, a "guest section editor" is appointed who fills the role normally played by the conflicted section editor. All members of the editorial board and reviewers are asked to indicate any conflict of interest when they agree to review a manuscript. 